not known, are low and vary for different types of violence.' So if doctors use these assessments they risk wrongly identifying their patient as at high risk of committing a serious crime, and then act in a way that is not in the best interests of that patient. Such an act would of course be inconsistent with the duties of a doctor as set out by the General Medical Council (GMC) in Good Medical Practice. ${ }^{2}$ It follows that while the prevalence of particular serious crimes in various patient populations is unknown or is known to be low, the use of these actuarial risk assessments will remain unethical. As Roychowdhury \& Ashhead conclude: '[structured professional judgement] tools used as checklists of risk factors without construction of risk scenarios or a risk management plan remains harmful and unethical practice.' In my opinion psychiatrists would value guidance on this issue from the GMC.

1 Roychowdhury A, Adshead G. Violence risk assessment as a medical intervention: ethical tensions. Psychiatr Bull 2014; 38: 75-82.

2 General Medical Council. Good Medical Practice. GMC, 2013.

Keith E. Dudleston, consultant psychiatrist (retired), Ivybridge, UK, email: dudleston@btinternet.com

doi: $10.1192 / p b .38 .4 .195 b$

\section{Risk assessment and evidence-based medicine}

The article by Roychowdhury \& Adshead starts to place violence risk assessment in the context of medical care. Although this is welcome, their partial defence of risk assessment in general, and of structured professional judgement in particular, is based on some significant distortions.

The first distortion is the gross overestimation of the power of risk assessment to discriminate between low-risk and high-risk people. The authors present a contingency table that they imagine shows the 'potential' outcomes of a violence risk assessment (Table 2). Using their tabulated data, a diagnostic odds ratio for risk assessment can be calculated to be 81 , indicating that the risk of violence in the high-risk group (50\%) is hugely higher than in the low-risk group (1.2\%). These figures are totally unrealistic. In fact, the diagnostic odds ratio of violence risk assessment in replication studies was recently estimated by meta-analysis ${ }^{2}$ to be 3 . Roychowdhury \& Adshead overestimate the discriminating power of risk assessment by 27 times. Moreover, even an unrealistically powerful risk assessment with diagnostic odds of 16 is of little or no value because of failure to detect potential violence in the low-risk group and the large proportion of false positives in the high-risk group. ${ }^{3}$

The second distortion relates to the underestimation of the precision of medical tests. In fact, the authors seem to have had difficulty finding any medical test with diagnostic odds that they could compare to a violence risk assessment. Instead they chose to compare two medical treatments. They argue that the high number-needed-to-treat as a result of a violence risk assessment is acceptable in psychiatry because in cardiology the number of bypass grafts needed to prevent one fatal outcome has been calculated to be $53 .{ }^{3}$ However, the meta-analysis they derived this figure from compared coronary bypass surgery to angioplasty - both of which are highly efficacious treatments for angina. ${ }^{3}$ In reality, medical tests that are used to diagnose conditions with serious implications for the patient are very accurate - biopsy is an excellent indicator of cancer and an angiogram a good indicator of coronary heart disease.

Despite these limitations, I support the authors' general idea of viewing risk assessment as a medical procedure. I would go further: surely violence risk assessment should be judged by the standards of evidence-based medicine. The real questions then become: (1) are there any rational interventions that can be justified in terms of cost and benefit that might reduce violence among high-risk patients (many of whom will not be violent) and yet should not be offered to low-risk patients (who commit as many or even the majority of acts of violence); and (2) is there evidence that shifting treatment resources from low-risk to high-risk people can, in any way, reduce overall levels of harm?

The answer to both these questions is no. ${ }^{4,5}$ There is no doubt that medical diagnostic tests serve as a good basis for medical treatment and that medical and surgical treatment can save lives. It is simply disingenuous to suggest that the same can be said of violence risk assessment.

Declaration of interest: M.L. has provided expert evidence in matters relating to risk assessment.

1 Roychowdhury A, Adshead G. Violence risk assessment as a medical intervention: ethical tensions. Psychiatr Bull 2014; 38: 75-82.

2 Singh JP, Grann M, Fazel S. Authorship bias in violence risk assessment? A systematic review and meta-analysis. PLoS One 2013; 8: e72484.

3 Hoffman SN, TenBrook JA, Wolf MP, Pauker SG, Salem DN, Wong JB. A meta-analysis of randomized controlled trials comparing coronary artery bypass graft with percutaneous transluminal coronary angioplasty: one- to eight-year outcomes. J Am Coll Cardiol 2003; 41: 1293-304.

4 Large MM, Ryan CJ, Callaghan S, Paton MB, Singh SP. Can violence risk assessment really assist in clinical decision-making? Aust N Z J Psychiatry 2014; 48: 286-8.

5 Wand T, Large M. Little evidence for the usefulness of violence risk assessment. Br J Psychiatry 2013; 202: 468.

Matthew Large, psychiatrist, School of Psychiatry, University of New South Wales, Sydney, Australia, email: mmbl@bigpond.com.

doi: $10.1192 / p b .38 .4 .196$

Author response: We thank Dr Matthew Large for his helpful comments. We wished to respond only by clarifying that the figures in Table 2 were from a hypothetical population, based on a hypothetical risk assessment tool with certain sensitivity and specificity values. The purpose was to illustrate that, even in risk assessments with unrealistic accuracy levels, the positive predictive value (PPV) was still low, as it was greatly influenced by the base rate. Any misleading odds ratios arising from the table was not intentional and arose (perhaps ironically) by chance.

Ashimesh Roychowdhury, consultant forensic psychiatrist and associate medical director, St Andrew's Healthcare, Northampton, email: ARoychowdhury@standrew.co.uk, and Gwen Adshead, consultant forensic medical psychotherapist, Broadmoor Hospital, Crowthorne, Berkshire.

doi: $10.1192 / \mathrm{pb} .38 .4 .196 \mathrm{a}$

\section{OCTET Study: flawed by type 2 error}

The OCTET study overcame many legal and ethical difficulties in setting up a randomised controlled trial (RCT) of community treatment orders (CTOs). ${ }^{1}$ We welcome the acknowledgment 